九州大学学術情報リポジトリ

Kyushu University Institutional Repository

\title{
An Analysis of the Factors Affecting Dairy Cow Production in the South East of Vietnam
}

\section{Loan, Chu Thi Kim}

Laboratory of Agricultural Economics, Division of International Agricultural Resource Economics and Business Administration, Department of Agricultural and Resource Economics, Graduate School of Bioresource and Bioenvironmental Sciences, Kyushu University

Yokogawa, Hiroshi

Laboratory of Agricultural Economics, Division of International Agricultural Resource Economics and Business Administration, Department of Agricultural and Resource Economics, Faculty of Agriculture, Kyushu University

Kawaguchi, Tsunemasa

Department of Economics, Faculty of Economics, Kyushu University

https://doi.org/10.5109/4643

出版情報：九州大学大学院農学研究院紀要. 50 (1)，pp.271-294，2005-02-01. Faculty of Agriculture, Kyushu University

バージョン：

権利関係 : 


\title{
An Analysis of the Factors Affecting Dairy Cow Production in the South East of Vietnam
}

\author{
CHU Thi Kim Loan ${ }^{1 *}$, Hiroshi YOKOGAWA \\ and Tsunemasa KAWAGUCHI ${ }^{2}$
}

\author{
Laboratory of Agricultural Economics, Division of International Agricultural Resource Economics \\ and Business Administration, Department of Agricultural and Resource Economics, \\ Faculty of Agriculture, Kyushu University, Fukuoka 812-8581, Japan \\ (Received September 30, 2004 and accepted November 11, 2004)
}

\begin{abstract}
This paper examines the factors affecting dairy production in Ho Chi Minh and Binh Duong provinces in 2003, based on original data collected from 80 dairy farm households and 40 non-dairy farm households. Descriptive statistics and production function analysis are the principal methods used in the study.

The findings indicate that dairy farmers in the region have been faced with limited quality of veterinary and breeding services, and a lack of capital and technical knowledge. In addition, herd management is poor, which results in farmers (especially beginners) having poor access to good cow breeds. Environmental pollution caused by dairy farms has also impacted negatively on the expansion of cow raising. The results from regression analyses of linear production functions indicate that milk yields of dairy households in the study areas are affected significantly and positively by complete feed, by-products from the brewery and cassava-processing industries, and experience of the household head. There is a significant difference between Ho Chi Minh and Binh Duong in the estimated variances of the error term and also in the estimated coefficients of the complete feed variable. Using the log-linear functional form, we get a similar conclusion but the significance levels of the estimated coefficients are found to be different from those in the linear one.
\end{abstract}

\section{INTRODUCTION}

The South East (SE) is one of 8 socio-economic regions in Vietnam, and has the highest dairy cow population. In 2002, the number of cows in the region was about 37 thousand head, accounting for 69 percent of the national cow herd (AFEC, 2002). The SE has a hot-wet climate with an average air temperature of around $27^{\circ} \mathrm{C}$ and an average relative humidity of almost 80 percent (based on data from the Statistical Office in Ho Chi Minh, 2002). The climatic condition of the region is evaluated to be not very suitable for purebred Holstein Friesian (HF) cows, so most dairy cattle raised here are HF crossbreeds. Compared to other regions of the country, the SE has a larger number of milk-processing factories, i.e. Truong Tho Milk Factory, Thong Nhat Milk Factory (Vinamilk Company), Vietnam Foremost Dairy Company, E \& N Vietnam Foods Company. However, at present they use mostly imported materials for processing. The volume of domestic milk materi-

\footnotetext{
1. Laboratory of Agricultural Economics, Division of International Agricultural Resource Economics and Business Administration, Department of Agricultural and Resource Economics, Graduate School of Bioresource and Bioenvironmental Sciences, Kyushu University

2 Department of Economics; Faculty of Economics, Kyushu Sangyo University

* Corresponding author (E-mail: chuloan@agr.kyushy-u.ac.jp)
} 
als bought by Vinamilk Company, a major milk buyer in the region, has met less than 10 percent of its demand (Van, 2002). The study on the economics of dairy cow production presented in a previous paper (Loan et al., 2004) indicates that farmers may receive relatively reasonable benefits from this occupation (e.g. an average net return is about 3 million VND per milking cow within a calving interval). Nevertheless, dairy farming in the region has not developed as fast and sustainably as was generally expected. Consequently, a question posed is what reasons are behind the situation of low speed of dairy development in the region. This study was conducted to contribute to answering the above question.

The specific purposes of the paper are, (1) to analyze major factors affecting the current situation of dairy cow production in the South East of Vietnam, (2) to quantify the effects of factors affecting milk yields in the region.

\section{METHODOLOGY}

A household survey was conducted in November and December 2003 in two provinces of the South East region, namely Binh Duong and Ho Chi Minh. The provinces were chosen based on their large contributions to the total milk production in the region. In total, a sample of 80 dairy farm households and 40 non-dairy farm households was randomly selected from two districts named Thuan An (Binh Duong province) and $\mathrm{Cu}$ Chi (Ho Chi Minh city). The total number of the households interviewed in each district was 60 .

Descriptive statistics and production function analysis were used as the major analytical methods to achieve the study objectives. Production functions that express the relationship between input levels and milk yield were estimated for both locations based on the survey data from 80 dairy farm households. Determinants of the model include information on input utilization (i.e. the levels of investment in complete feed, by-products from the brewery and cassava-processing industries, green fodder, dry straw and labor) and others (e.g. the number of milking cows, experience in dairy farming of the household heads and dummy variables).

\section{AN ANALYSIS OF THE FACTORS AFFECTING DAIRY PRODUCTION}

\section{General characteristics of the sample}

Generally, household heads in the study areas have a relatively low educational level. On average, they attended almost 6 years in school. This may be largely explained by the fact that the South of Vietnam was only liberated and reunified with the north in 1975 , so people born before 1970 had poorer access to education. With respect to experience in dairy farming, raising cows is still a new occupation in both locations. On average, farmers in Ho Chi Minh and Binh Duong had practiced dairy production for 5.7 and 4 years respectively (Table 1).

With regard to land holdings, Binh Duong farmers hold larger areas than Ho Chi Minh farmers. On average, a household located in Binh Duong held 5,203 $\mathrm{m}^{2}$, while this indicator was $3,697 \mathrm{~m}^{2}$ in the case of Ho Chi Minh households. However, levels of household income are not so different between the two locations. A household with almost 5 
Table 1. General characteristics of the sampled dairy households.

\begin{tabular}{lcrr}
\hline \multicolumn{1}{c}{ Items } & Unit & Ho Chi Minh & Binh Duong \\
\hline 1. Average age of household heads & years & 47.1 & 45.8 \\
2. Experience in dairy farming & years & 5.7 & 4.0 \\
3. Average education level of household heads & years & 6.0 & 5.9 \\
4. Average household size & persons & 4.7 & 4.4 \\
5. Average land holding of households & m $^{2}$ & $3,696.9$ & $5,203.0$ \\
6. Average household income & thousand VND & $41,065.1$ & $40,802.1$ \\
\multicolumn{1}{c}{ Of which, the income from raising cows } & thousand VND & $25,927.4$ & $27,164.4$ \\
\hline
\end{tabular}

Source: Survey, 2003

persons enjoyed an annual average income of around 40 million VND. This income level is assessed to be threefold higher than that of rice producing households (see Hien, 2003). Raising cows contributed significantly to the above achievement as it accounts for over 60 percent of the total household income.

\section{Factors affecting dairy cow production in the SE}

There are a lot of the factors affecting dairy production in the region. They include both internal and external factors, which may impact negatively and/or positively on development of the sector. External factors are those relating to the general production environment and beyond the control of dairy households, such as policies of the government, support from related organizations (i.e. veterinary and breeding units, extension offices, the network of milk collecting stations and financial organizations), availability of market and natural conditions (e.g., temperatures, humidity and rainfall). Internal factors are considered to be those that relate to individual characteristics of households and that can be partially or wholly controlled by them (e.g. level of environmental pollution caused by their own dairy farms; household resources such as landholdings,

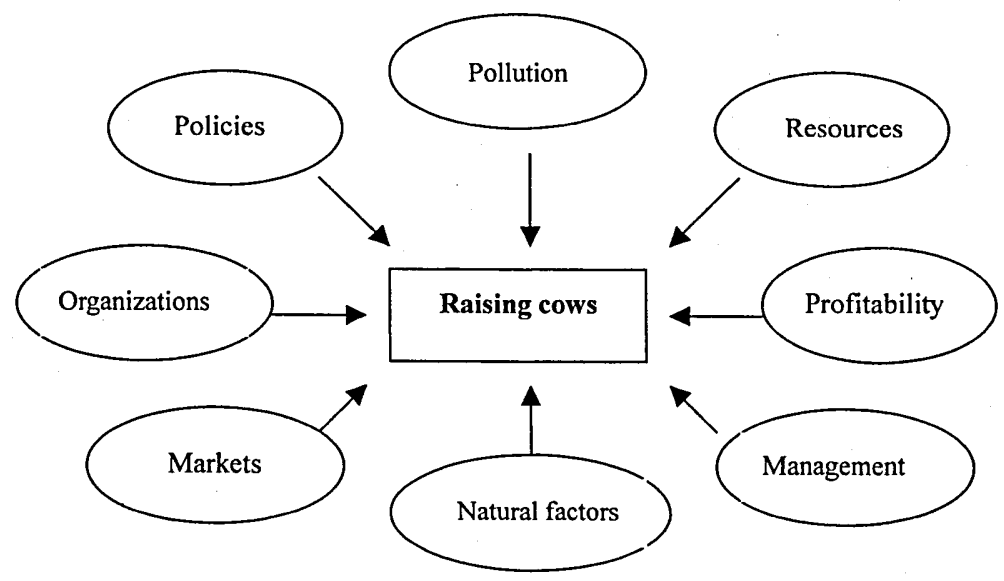

Fig. 1. Major factors affecting dairy production in the SE. 
labor, grass fields and management skills; profitability of dairy production; etc.). In this paper we only focus on some factors significantly affecting dairy cow production in the region (Fig. 1). The following sections will briefly describe those factors.

Policies of the government

The Vietnamese government has currently given a high priority to the development of the animal sector in general and dairy production in particular. Policies have given incentives to farm households to enter and expand their animal production activities. Some of these policies are summarized as follows:

1. Decree No. 13/CP on Extensional Tasks dated March $2^{\text {mid }} 1993$ gave a basis to form extension networks from central to local levels. Its foundation has helped give farmers more chance to be trained and provided with technical and economic information.

2. Decree No. 14/CP on Management of Domestic Animals dated March $19^{\text {th }} 1996$ stipulated clearly the conditions related to the production, import, export, etc. of animal breeds. The decree stimulated and gave advantages to organizations and individuals to study and produce improved animal breeds in Vietnam.

3. Decree No. 15/CP dated March $19^{\text {th }} 1996$ on Management of Feed issued some regulations, mechanisms and policies to encourage organizations and individuals to produce animal feed in Vietnam. Combined with the passage of the new investment law of 1994, the decree impacted significantly on the feed processing industry. New domestic and foreign investment has been made in the sector, and so supply and quality of commercial feed has improved and increased considerably.

4. Resolution No. 03/NQ-CP dated February $2^{\text {"wl }} 2000$ on Development of Large Scale Farms has given incentives (i.e. long term land use, tax exemption, low interest.loans) to farm households in the nation to expand their farm sizes. Farmers with available resources (e.g., good knowledge and/or high capital, etc.) have been given incentives to invest and develop agricultural production. As a result, over 5 thousand large-scale farms in the livestock sector have been formed in Vietnam so far (Anh, 2003).

5. Decision No. 167/QD-TTg dated October 26"1 2001 on Measures and Policies for Dairy Cow Development for the period 2001-2010 has given large opportunities for the growth of the dairy sector. Based on this decision, units of scientific research and training will be invested and upgraded; milk-buying and -processing units may receive an investment incentive on tax; producers can get easier access to credit and information, etc. The government's target is 200 thousand head of dairy cows meeting 40 percent of domestic milk demand by 2010 .

It is useful to note here that animal production may result in environmental pollution if wastes (i.e. manure and urine) are not managed properly. Therefore, government policies related to environmental protection may also impact on development of the sector. In theory, every polluter in Vietnam is controlled by the law of environment protection enacted in January 1994 and the polluter-pays principle. In addition to the law, there are some other environmental legal initiatives such as government decrees, ordinances, interministerial circulars and guidelines. However, the law and those legal documents have not been fully implemented in practice. One of the reasons may be that pollution control generally appears to be non-productive in the short-term, while the existing administrative system judges the performance of government officials almost entirely by how much they are able to increase their region's economic growth. Hence, they are 
sometimes likely to ignore polluters (Phuong, 1996). It is also reported that national regulations on environmental protection mainly pay attention to the industrial enterprises which make more pollutants, and so there is a need for livestock-specific regulations on waste treatment (Hoa and Luan, 2003).

Breeding and veterinary services in the study areas

The survey revealed that the existing situation of breeding and veterinary services in the study areas was quite poor, which resulted in some negative impacts on dairy production. On average, a dairy farmer knew 4.2 veterinarians and 3.4 breeders. These numbers are assessed to be not as low as other locations such as Hanoi and Ha Tay. However, only a small percentage of them had high skills. Farmers indicated that in some cases of diseases they had to ask veterinarians from other places located around $10-30 \mathrm{~km}$ from their villages (e.g. Hooc Mon, District 12, Ho Chi Minh center, Thu Dau Mot town) to treat their dairy cows. Long distances, associated with other factors (e.g. poor roads, bad weather, etc.) meant that some cows could not be treated in time. As shown in Table 2, about 35 percent of the total interviewed households did not agree with the statement that veterinary units helped them treat diseases of their cows in time. Moreover, farmers in the above cases had to depend completely on those veterinarians and accept any level of cost for treatment offered by them. Around 20 percent of the total surveyed households considered the quality of veterinary services as "bad", while some 40 percent of them regarded it as "normal". Nevertheless, state veterinary units in the region have helped farmers to take precautions against diseases by providing them with periodic vaccines. Almost all of the interviewed dairy farmers agreed or strongly agreed with that evaluation.

All milking cows in the sample are supplied with an artificial insemination (AI) service, but the quality of the service is still limited. About one-third of the respondents considered it as "bad". Among the total sample of 315 cows inseminated in 2003, only

Table 2. Dairy farmers' perception on the quality of veterinary and AI services.

(Unit: percent)

\begin{tabular}{lrrrrr}
\hline \multicolumn{1}{c}{ Questions } & 1 & 2 & 3 & 4 & 5 \\
\hline I. In Ho Chi Minh & & & & & \\
1. How is the quality of veterinary service? & 0.0 & 37.5 & 42.5 & 20.0 & 0.0 \\
2. How is the quality of artificial insemination service? & 0.0 & 22.5 & 45.0 & 32.5 & 0.0 \\
3. Have veterinary units helped you take precautions & & & & & \\
$\quad$ against diseases? & 22.5 & 75.0 & 2.5 & 0.0 & 0.0 \\
4. Have veterinary units helped you treat diseases in time? & 0.0 & 45.0 & 35.0 & 0.0 & 20.0 \\
II. In Binh Duong & & & & & \\
1. How is the quality of veterinary service? & 0.0 & 40.0 & 37.5 & 22.5 & 0.0 \\
2. How is the quality of artificial insemination service? & 0.0 & 22.5 & 40.0 & 37.5 & 0.0 \\
3. Have veterinary units helped you take precautions & & & & & \\
$\quad$ against diseases? & 30.0 & 70.0 & 0.0 & 0.0 & 0.0 \\
4. Have veterinary units helped you treat diseases in time? & 0.0 & 45.0 & 37.5 & 0.0 & 17.5 \\
\hline
\end{tabular}

Note: $1,2,3,4$ and 5 denote the qualitative levels. They are very good, good, normal, bad and very bad, respectively in the case of the question 1 and 2 . Meantime, they indicate strongly agree, agree, disagree, strongly disagree and undecided, respectively in the case of the question 3 and 4 .

Source: Survey, 2003 
27.3 percent of them fell pregnant after the first insemination (Table 3). The proportions of successful inseminations after 2 and over 2 times were 55.2 and 17.5 percent respectively ${ }^{(1)}$. The failure of breeding increases milk production cost. For example, farmers in Binh Duong had to pay 50 thousand VND more for the second AI service. Some households expended a package cost of 300,500 or 1000 thousand VND to get a pregnant cow. Moreover, the interval between two consecutive calvings was also lengthened, which will affect total milk production over the whole life of the cow.

Table 3. Costs and results of AI services.

\begin{tabular}{|c|c|c|c|c|c|c|}
\hline \multirow{2}{*}{ Indicators } & \multicolumn{3}{|c|}{ Ho Chi Minh } & \multicolumn{3}{|c|}{ Binh Duong } \\
\hline & 1 & 2. & $>2$ & 1 & 2 & $>2$ \\
\hline $\begin{array}{l}\text { 1. The number of cows that fell pregnant } \\
\text { after the respective times of AI (heads) }\end{array}$ & 40 & 88 & 29 & 46 & 86 & 26 \\
\hline Share in the total (\%) & 25.5 & 56.0 & 18.5 & 29.1 & 54.4 & 16.5 \\
\hline 2. Accumulative cost (thousand VND) & 50 & 90 & 120 & 60 & 110 & 150 \\
\hline
\end{tabular}

Note: 1,2 and $>3$ indicate the number of AI times needed to get a cow pregnant. Source: Survey, 2003

\section{Breed supply sources}

Incentive policies of the government, the benefits of dairy production and the improvement of the milk procurement network in the region over the past years could be major factors that have attracted farm households to enter the sector. While a national source of cow breeds is limited, an increase in demand has resulted in a shortage of breeds in the region and pushed their prices higher. The results of the survey indicated that the price of one 2-3 age crossbred heifer increased from VND 13-15 million in 2001 to VND 16-21 million in 2003. Due to the lack of breeding stock, almost all female calves born have been kept for milking purpose without any selection procedures. This might negatively impact on the general development of dairy production in the region.

Regarding the sources of breed supply, about one-third of total milking cows raised in dairy households were bought from their friends and neighbors (Table 4). In addition, purchasing the cows from middlemen was also quite common in the study areas. Only a small proportion of the milking cow population raised in farm households was from cooperatives or breed centers (e.g. the breed centers supplied only 9.6 percent of the total milking cows to farmers). A major reason may be because of their higher prices and long distances between farms and breeding centers. The above fact shows that formal organizations in the region still play a limited role in providing producers with cow breeds. While farmers' level of herd management is low (see later paragraphs), the current structure of breed supply sources may not be good for the development of dairy production.

(1) Of course, there are some other factors affecting the lack of success using AI, i.e. low quality of semen, characteristics of cows (hormonal disorder, anatomical defects, etc). However, a low conception rate is still considered as an indicator showing the poor quality of AI services in the region. 
Table 4. Sources of breed supply.

\begin{tabular}{lrrrrrrrr}
\hline \multirow{2}{*}{ Sources of breed } & \multicolumn{2}{c}{ Ho Chi Minh } & & \multicolumn{2}{c}{ Binh Duong } & & \multicolumn{2}{c}{ Both the provinces } \\
\cline { 2 - 3 } \cline { 8 - 9 } & Head & Percent & & Head & Percent & & Head & Percent \\
\hline 1. Friends and neighbors & 44 & 31.2 & & 54 & 41.5 & & 98 & 36.2 \\
2. Own calves & 55 & 39.0 & & 21 & 16.2 & & 76 & 28.1 \\
3. Breed centers & 1 & 0.7 & & 25 & 19.2 & & 26 & 9.6 \\
4. Relatives & 2 & 1.4 & & 0 & 0.0 & & 2 & 0.7 \\
5. Cooperatives & 10 & 7.1 & & 2 & 1.6 & & 12 & 4.4 \\
6. Others & 29 & 20.6 & & 28 & 21.5 & & 57 & 21.0 \\
$\quad$ Total & 141 & 100.0 & & 130 & 100.0 & & 271 & 100.0 \\
\hline
\end{tabular}

Note: Above structure was calculated for the milking cow herd.

Source: Survey, 2003

\section{Access to credit}

Raising cows requires a high level of resource input and management. Therefore, easy access to credit and technical information is essential for the development of milk production. The survey results show that 35 and 45 percent of the total interviewed households in Ho Chi Minh and Binh Duong respectively obtained credit from different financial organizations in 2003. Among the borrowers, about 70 percent of them had access to formal sources such as banks of agriculture and rural development, other banks, women unions and farmers' associations with relatively high loan amounts (i.e. over 10 million VND) (Table 5). This indicates that the formal financial organizations in the region have been playing an important role in providing dairy farmers with working capital. However, some dairy households still had difficulty in obtaining credit from those

Table 5. Dairy farmers' access to credit in the study areas.

\begin{tabular}{lrcrc}
\hline \multicolumn{1}{c}{ Sources } & $\begin{array}{c}\text { \% of total } \\
\text { borrowers }\end{array}$ & $\begin{array}{c}\text { Aver. amount of loan } \\
\text { (mill. VND) }\end{array}$ & $\begin{array}{r}\text { Duration } \\
\text { (month) }\end{array}$ & $\begin{array}{c}\text { Interest rate } \\
\text { (\%/month) }\end{array}$ \\
\hline In Ho Chi Minh & & & & \\
1. Agricultural and RD banks & 14.3 & 20.0 & 24.0 & 1.0 \\
2. Other banks & 35.7 & 14.0 & 24.0 & 0.9 \\
3. Women unions & 14.3 & 15.0 & 24.0 & 0.8 \\
4. Farmers' associations & 7.1 & 10.0 & 36.0 & 0.5 \\
5. Relatives & 14.3 & 4.0 & Unlimited & 0.0 \\
6. Village lenders & 14.3 & 4.0 & - & 1.4 \\
In Binh Duong & & & & \\
1. Agricultural and RD banks & 38.9 & 27.3 & 37.1 & 0.9 \\
2. Other banks & 5.5 & 40.0 & 60.0 & 0.8 \\
3. Farmers' associations & 27.8 & 18.0 & 36.0 & 0.5 \\
4. Friends & 16.7 & 22.3 & - & 0.2 \\
5. Relatives & 5.5 & 10.0 & Unlimited & 0.0 \\
6. Village lenders & 5.5 & 5.0 & Unlimited & 1.5 \\
\hline
\end{tabular}

Note: RD and Aver. denote rural development and average, respectively.

Source: Survey, 2003 
sources due to complicated lending procedures, requirements of collateral and other criteria. As a result, almost 10 percent of the borrowers had to borrow from village lenders at higher interest rates (e.g. 1.4 or 1.5 percent per month).

Access to technical information

An analysis of the survey data indicates that co-producers ${ }^{(2)}$ and extension officials are the most important information sources for dairy households. In Ho Chi Minh, unskilled producers usually learn from the experience of senior farmers and then apply it to their own dairy farms. In addition, there is also an exchange of experience among dairy farmers to improve their knowledge. It was found that some dairy farmers often meet each other in a shop named Cafe - Cow at noon to share information related to cows. Therefore, most of the respondents in Ho Chi Minh considered co-producers as the most important information source with a total score of 177 (Table 6). In Binh Duong, beginners had a chance to get access to production techniques through participation in training courses held by extension centers (or the milk processing factory). Moreover, dairy households in this location are dispersedly throughout the village, which makes it more difficult for them to share everyday information. This may partially explain the fact that Binh Duong farmers considered extension officials as their most important information source.

Generally, the formal organizations in the region (e.g. extension centers and milk-processing factories) contributed considerably in disseminating production techniques to dairy farmers in recent years. However, it was said that training courses

Table 6. Ranking sources of technical information by dairy farmers.

\begin{tabular}{|c|c|c|c|c|c|c|c|}
\hline \multirow{2}{*}{ Sources } & \multicolumn{5}{|c|}{ Percentage of farmers responses with } & \multirow{2}{*}{$\begin{array}{l}\text { Responding } \\
\text { percentage }\end{array}$} & \multirow{2}{*}{$\begin{array}{l}\text { Total } \\
\text { score }\end{array}$} \\
\hline & $1^{\text {si }}$ & $2^{\text {mid }}$ & $3^{\text {ris }}$ & $4^{\text {th }}$ & $5^{\text {th }}$ & & \\
\hline \multicolumn{8}{|l|}{ In Ho Chi Minh } \\
\hline - Co-producers & 60.0 & 30.0 & 2.5 & 7.5 & 0.0 & 100.0 & 177 \\
\hline - Extension officials & 32.5 & 45.0 & 17.5 & 2.5 & 2.5 & 100.0 & 161 \\
\hline - Radio and television & 0.0 & 0.0 & 27.5 & 47.5 & 17.5 & 92.5 & 78 \\
\hline - Relatives & 2.5 & 15.0 & 22.5 & 15.0 & 17.5 & 72.5 & 75 \\
\hline - Books, newspapers and journals & 5.0 & 5.0 & 10.0 & 17.5 & 42.5 & 80.0 & 61 \\
\hline - Others & 0.0 & 5.0 & 17.5 & 7.5 & 20.0 & 50.0 & 43 \\
\hline \multicolumn{8}{|l|}{ In Binh Duong } \\
\hline - Extension officials & 62.5 & 30.0 & 7.5 & 0.0 & 0.0 & 100.0 & 182 \\
\hline - Co-producers & 25.0 & 60.0 & 10.0 & 2.5 & 2.5 & 100.0 & 161 \\
\hline - Radio and television & 0.0 & 0.0 & 30.0 & 52.5 & 15.0 & 97.5 & 84 \\
\hline - Relatives & 5.0 & 5.0 & 32.5 & 22.5 & 20.0 & 85.0 & 83 \\
\hline - Others & 7.5 & 2.5 & 17.5 & 5.0 & 17.5 & 50.0 & 51 \\
\hline - Books, newspapers and journals & 0.0 & 2.5 & 2.5 & 17.5 & 47.5 & 70.0 & 40 \\
\hline
\end{tabular}

Note: " 1 st" to " 5 "l". under "Percentage of farmers" indicates farmers' ranks to respective sources. To calculate total score, first was accorded 5 score, second equals 4 score, and fifth equal 1 score.

Source: Survey, 2003

\footnotetext{
(2) The term refers to people who are friends and/or neighbors of the respondents. They have also been practicing dairy farming.
} 
were not regularly held and only a limited number of producers had chances to participate in these, so some farmers still lacked the technical knowledge needed to manage their dairy farms.

Market for and price of raw milk

At present, there are 7 large milk-processing factories located in the region, almost all of which use a huge amount of imported milk materials. Vinamilk Company, with three milk factories situated in Ho Chi Minh, is a major milk buyer in the region. According to Van (2003), most milk collected at the dairy farms by Vinamilk is processed into UHT milk. Vinamilk imports about 98 percent of the materials needed to process condensed and powdered milk. Furthermore, demand for milk and dairy products is forecasted to continue growing in future years due to an increase in household income, population growth and urbanization. In fact, the annual consumption of milk and dairy products per capita in Vietnam grew from $3.7 \mathrm{~kg}$ in 1995 to $6.5 \mathrm{~kg}^{(3)}$ in 2000 (Van, 2003). Moreover, these levels of consumption are still very low compared to those of other countries. For example, the daily per capita consumption of milk and dairy products in Japan was $254.2 \mathrm{~g}$ in 1999 (or $92.8 \mathrm{~kg} /$ year) (Japan Dairy Council, 2002). All this indicates that the potential for the raw milk market in Vietnam in general and in the region in particular could be large.

The price of raw milk is predetermined by buyers (i.e. milk factories) according to their quality criteria. Consequently, the best way for farmers to obtain a higher level of return is an improvement in milk quality and/or a decrease in costs per $1 \mathrm{~kg}$ of milk produced. However, high and unstable feed prices considerably affect the costs and thus the incomes of dairy households. Experienced farmers complain that the milk price offered by Vinamilk Company has been fixed from 1995 to now (i.e. 3,200 VND at its milk collection stations), while the prices of feed for dairy cattle have significantly changed. For example, the price of complete feed increased from about 2,000 VND/kg in 1996 to almost 2,700 VND/kg in 1997 and 2,800 VND/kg in 1998 (HDARD, 2003). Although the price of complete feed was reduced to around $2,400 \mathrm{VND} / \mathrm{kg}$ in 2003 , about 42.5 percent of the total interviewed households felt unsatisfied with the current milk price. Only 9 percent of them were satisfied, while the remainder considered it an acceptable price level at the existing input prices. Farmers want the government to have some policy that contributes to reducing the price of complete feed or increasing the milk price, so that the ratio of output to input is kept constant. Based on the research of Christopher et al. (2003), the average price of concentrated feed paid by Thailand farmers was 5.0 baht per $\mathrm{kg}$, while the average price of milk they received was $11.2 \mathrm{baht} / \mathrm{kg}$ in $2002^{(4)}$. In other words, the ratio of milk price to concentrated feed price in Thailand was around 2.2. Our trip to Okinawa prefecture of Japan in March 2003 also indicated that the value of $1 \mathrm{~kg}$ of raw milk in the region was equivalent to that of about $2.8 \mathrm{~kg}$ of complete feed. The above ratios are much higher than the figure of 1.4 for the South East region of Vietnam.

It would be better to have time series data of the feed price to show changes. However, because of the difficulty in getting this information, we used prices of some agricultural products over the period of 1995-2002 to partially express that fluctuation

(3) The consumption of milk and dairy products is in liquid milk equivalents

(4) US $\$ 1=42.96$ baht, based on 2002 foreign exchange rates (Christopher, 2003). 
(Fig. 2). According to Lich (2003), feed-processing factories in Vietnam have to import a large volume of raw materials (e.g., maize, soybean meals, fish meals, lysine, etc.) annually at relatively high duty levels of 5-20 percent. The high cost of imported materials combined with the fluctuation of their prices in the world market might be one of the reasons leading to high, unstable prices of concentrated and complete feeds.

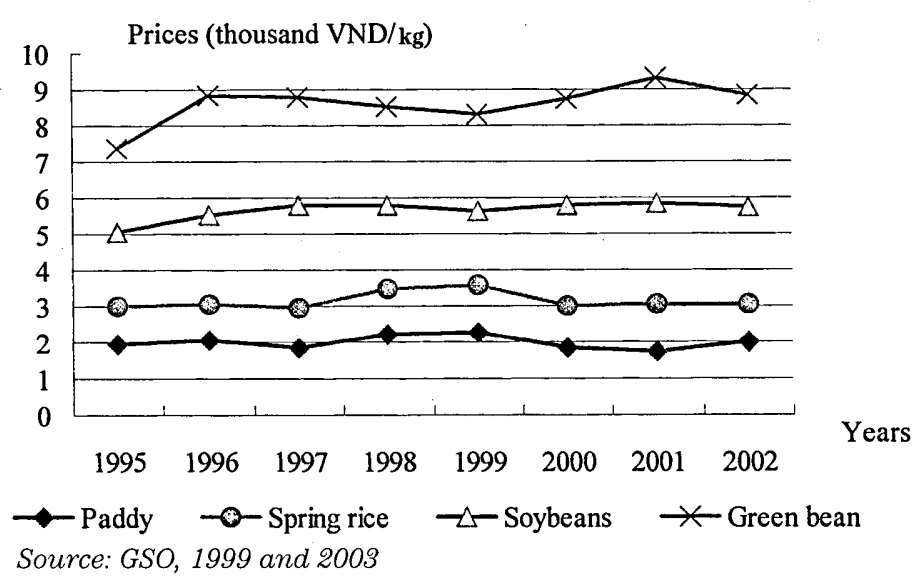

Fig. 2. Average retail prices of selected agricultural products during 1995-2002.

\section{Fodder production in the region}

The survey reveals that many farmers in the study area have been faced with a lack of green fodder, especially in the dry season. There were around one-quarter of the total interviewed households who were completely dependent on grass collection, while the number of households cultivating enough grass for their cows throughout a year was less than one-fifth (Fig. 3). Commonly, dairy farmers choose a combination of grass cultivation and collection as their source of fodder supply. Almost one-third and half of the sampled households in Ho Chi Minh and Binh Duong respectively fell under this category. About 11 percent of the total surveyed households bought either part or all of the green fodder required to feed their cows. However, it was found that almost all the green grass sold in the market was collected from public areas such as river banks and fallow areas, so its quality was not high (e.g. low nutrient levels and unclean). Furthermore, the source of natural grass was not stable, so farmers sometimes had difficulty in getting it. On average, the grass-cultivated area per dairy cow was only 158 and $178 \mathrm{~m}^{2(5)}$ in Ho Chi Minh and Binh Duong, respectively. The above fact indicates that expansion of grass fields in the region may be very necessary for the sustainable development of dairy production.

Level of herd management

Currently, the level of cow herd management in the region has been partially improved, but is in general still limited. In 2003, the Ho Chi Minh Livestock Department

(5) Note: These are averages based on the total number of dairy cows in all the interviewed households (both non-grass growing and grass growing households) 
By sources of green fodder supply

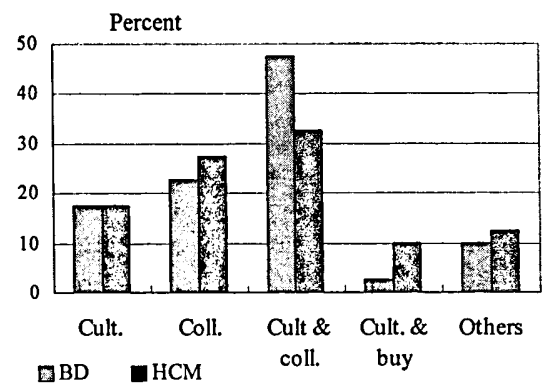

By months farmers can provide cultivated fodder

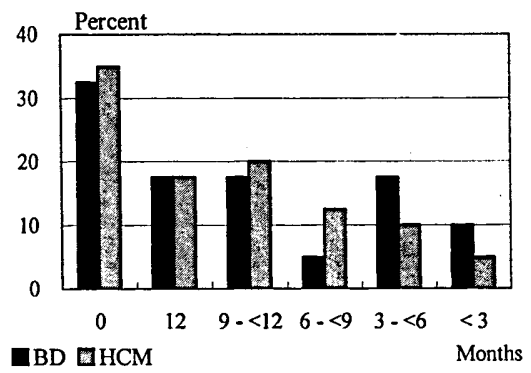

Note: cult. and coll. denote cultivation and collection, respectively;

$\mathrm{BD}$ and $\mathrm{HCM}$ stand for Binh Duong and Ho Chi Minh, respectively.

Source: Survey, 2003

Fig. 3. Proportion of the households by sources of green fodder supply and by months they are able to provide their dairy cows with cultivated fodder.

cooperated with local authorities to guide dairy households to report information related to dairy cow production (e.g., birth dates, milk yields, sources of semen used to inseminate, etc.). Producers in the location were provided with notebooks which contained forms to record herd management details. However, the survey revealed that dairy farmers had recorded in the first few months and then tended to ignore the recording forms. At the time of the survey, there were almost 48 and 55 percent of the total interviewed households in Ho Chi Minh and Binh Duong respectively who had no reporting activity during the past 5 months (Table 7). Even the farmers recording only paid attention to the milk yields and the dates of AI to estimate their incomes and the time of cows' calving. They were not much concerned about the codes of semen and the characteristics of bulls providing sperm. About 71 percent of the total sample households asked breeders about the sperm origins, but only 25 percent of the total sample recorded this information

Table 7. Situation of recording in the surveyed dairy households.

\begin{tabular}{|c|c|c|c|c|c|c|}
\hline \multirow{2}{*}{ Activities } & \multicolumn{2}{|c|}{ Ho Chi Minh } & \multicolumn{2}{|c|}{ Binh Duong } & \multicolumn{2}{|c|}{ The region } \\
\hline & No. hh & Percent & No. hh & Percent & No. hh & Percent \\
\hline 1. Having the notebook to record & 33 & 82.5 & 29 & 72.5 & 62 & 77.5 \\
\hline 2. Having no recording activity during & & & & & & \\
\hline the past 5 months & 19 & 47.5 & 22 & 55.0 & 41 & 51.3 \\
\hline 3. Asking about sources of semen & 29 & 72.5 & 28 & 70.0 & 57 & 71.3 \\
\hline 4. Asking about the characteristics of & & & & & & \\
\hline bulls providing semen & 15 & 37.5 & 12 & 30.0 & 27 & 33.8 \\
\hline 5. Recording the above information & 11 & 27.5 & 9 & 22.5 & 20 & 25.0 \\
\hline 6. Receiving the certification of AI & 17 & 42.5 & 21 & 52.5 & 38 & 47.5 \\
\hline
\end{tabular}

Note: No. hh denote the number of household.

Source: Survey, 2003 
related to semen. Consequently, many dairy cows in the study areas did not have personal records of their parents, health status and milk production, etc. As a result, farmers usually have poor access to good cow breeds when starting their dairy farms. They are not provided with adequate and reliable information about the cows they buy. Some farmers bought dairy cows with low yields, which made them unsatisfied, and so they hesitate to expand their dairy herd.

Use of dairy wastes and environmental pollution

If dairy farm wastes such as manure and liquid wastes (urine and waste water) are not properly managed, an increase in the cow population will create pollution problems, which in turn impacts negatively on the expansion of dairy production. Therefore, the development of dairy farms needs to be mindful of what is needed to prevent further environmental pollution.

* Use of dairy wastes

The survey found that cow manure was removed from the sheds everyday and mainly stored at nearby places. Almost 9 percent of the total surveyed households in the study areas had installed biogas generators to dispose dairy farm wastes (Table 8). The remainder commonly used a traditional method to treat them, i.e. the manure is piled in a hole or an open area and then covered by rice husks or straw. After several months, the manure was mainly sold to cultivators in other locations for use as fertilizer. Its farm-gate price was low, ranging from 30 to 50 thousand VND/ton ( 1 US $\$=15.5$ thousand VND at the time of the survey). A small amount of the cow manure was spread over the soil surface of an open area to be dried by sunshine (i.e. only one dairy household in the sample used this method). Dry manure was commonly purchased by persons growing ornamental plants at prices of 200-300 thousand VND/ton. About 20 percent of the surveyed households utilized the whole manure for their own activities such as fertilizing crops and raising worms. Over 40 percent of the sampled households only used a part of the manure, and the remainder was sold to cultivators.

The use of dairy wastes is briefly illustrated in Fig. 4. So far, the liquid wastes of dairy farms has not been fully used and managed by households. About 7.5 percent of the total surveyed households, who have fodder plots located next to the cow sheds, made small gutters to directly drain the liquid wastes to the field. The remaining households mainly

Table 8. Use of cow manure in the surveyed dairy households.

\begin{tabular}{|c|c|c|c|c|c|c|}
\hline \multirow{2}{*}{ Use of cow manure } & \multicolumn{2}{|c|}{ Ho Chi Minh } & \multicolumn{2}{|c|}{ Binh Duong } & \multicolumn{2}{|c|}{ Both locations } \\
\hline & No. hh & $\overline{\text { Percent }}$ & No. hh & Percent & No. hh & Percent \\
\hline - Making biogas & 3 & 7.5 & 4 & 10.0 & 7 & 8.8 \\
\hline - For sale & 18 & 45.0 & 3 & 7.5 & 21 & 26.3 \\
\hline $\begin{array}{l}\text { - For other activities of the family } \\
\text { (except for making biogas) } \\
\text { - For both family's other activities }\end{array}$ & 4 & 10.0 & 12 & 30.0 & 16 & 20.0 \\
\hline and sale (except for making biogas) & 14 & 35.0 & 21 & 52.5 & 35 & 43.8 \\
\hline - Others & 1 & 2.5 & 0 & 0.0 & 1 & 1.3 \\
\hline
\end{tabular}

Note: No.hh denote the number of households.

Source: Survey, 2003 


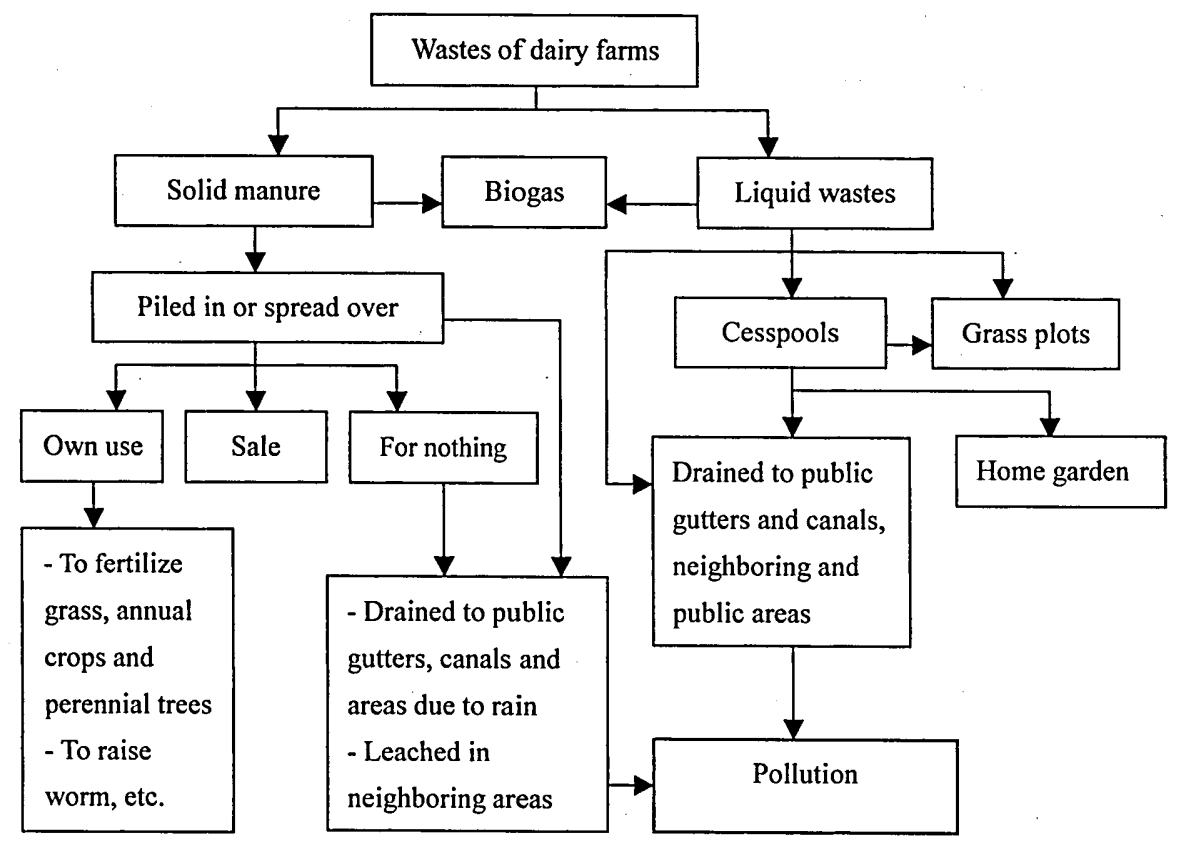

Fig. 4. Use of dairy farm wastes in the surveyed dairy households.

contained them in cesspools for watering and fertilizing perennial crops and grass cultivated in their home garden. However, the respondents indicate that the volume of liquid wastes was quite large due to the frequency of hygienic activities (i.e. cleaning the shed and cows), which resulted in them having more waste material than they could store or use. In fact, it is not easy for farmers to transport this amount of liquid wastes to other places, so it is usually drained to public gutters and canals. As shown in the diagram, the manure piles and the liquid wastes of dairy farms under the impacts of other factors (e.g., heavy rain, strong wind, the poor situation of drainage networks, etc.) may be a source of environmental pollution in the region.

* Perception of households on negative effects of dairying

There are different approaches that can be used to evaluate the level of environmental pollution: an analysis of quality indicators of water, air and soil (e.g., pH level, levels of chloride and nitrate, ammonia, carbon dioxide and so on) and/or an examination of farmers' evaluation of the negative effects of a given activity. In this paper, to partially understand the level of pollution in the region we only consider the perceptions on air and water pollution of dairy producers and non-dairy farmers living nearby dairy households. The results are illustrated in Table 9.

There seems to be a general tendency for dairy households to be defensive in their answers because of their suspicion that they may be required to discontinue milk production or to pay an environmental control fee. However, 38.8 percent of the total dairy households are still bothered by the negative effects coming from their dairy farms. 
Table 9. Perception of households on the effects of dairying on air and water.

\begin{tabular}{|c|c|c|c|c|}
\hline \multirow{2}{*}{ Perception of households } & \multicolumn{2}{|c|}{ Dairy farm $(n=80)$} & \multicolumn{2}{|c|}{ Non-dairy farm $(n=40)$} \\
\hline & No of hh & Percent & No of hh & Percent \\
\hline \multicolumn{5}{|l|}{ 1. Has dairying caused nuisances to you? } \\
\hline- Yes & 31 & 38.8 & 25 & 62.5 \\
\hline \multicolumn{5}{|l|}{ If yes, what is the most effect } \\
\hline - Malodors & 22 & 27.5 & 22 & 55.0 \\
\hline -Flies & 9 & 11.5 & 2 & 5.0 \\
\hline - Others (i.e. bellowing noise) & 0 & 0.0 & 1 & 2.5 \\
\hline \multicolumn{5}{|l|}{ 2. Has dairying affected quality of water? } \\
\hline - Yes & 47 & 58.8 & 29 & 72.5 \\
\hline \multicolumn{5}{|c|}{ If yes, (1) Water has become dirty and polluted } \\
\hline - Agree & 39 & 48.8 & 25 & 62.5 \\
\hline - Disagree & 5 & 6.3 & 2 & 5.0 \\
\hline \multicolumn{5}{|l|}{ (2) Water now emits foul odor } \\
\hline - Agree & 19 & 23.8 & 16 & 40.0 \\
\hline - Disagree & 25 & 31.3 & 7 & 17.5 \\
\hline
\end{tabular}

Note: Percentage may not add to $100 \%$ because some households did not give the answer or were undecided. No of hh denote the number of households.

Source: Survey, 2003

Specific nuisances ranked from high to low were malodors (bad smell), flies and bellowing noise. Almost 49 percent of total dairy households agreed with the judgment that the quality of water in public gutters, canals and ponds has become dirty and polluted, while only 24 percent of them admitted the water had a foul odor. Corresponding percentages of total non-dairy farm households were found to be higher. About 63 percent of the surveyed non-dairy farmers said that they had been affected by the nuisances of dairying. This may be one of the reasons resulting in conflict or an unfriendly relationship between dairy farmers and their neighbors, which becomes another constraint to the expansion of dairy farming. The above analysis indicates that environmental pollution has become a problem in the region. Consequently, it needs to be addressed by dairy households themselves and the government as well.

\section{A PRODUCTION FUNCTION ANALYSIS OF FACTORS AFFECTING MILK YIELD}

\section{Data and empirical model}

Cross-sectional data for a sample of 80 dairy households were used to estimate both linear and Cobb-Douglas production functions. A major purpose of using two functional forms is to compare whether there is any difference in their outcomes. The specific models estimated are the following:

* For a linear functional form:

$$
Y=\beta_{0}+\beta_{1} F e+\beta_{2} B r+\beta_{33} C a+\beta_{4} D a+\beta_{5} C o+\beta_{6} F_{O}+\beta_{7} S t+\beta_{8} E x+\beta_{9} D_{1}+\beta_{10} D_{2}+u
$$

* For a Cobb-Douglas production function:

$$
\begin{aligned}
& \ln Y=\ln \beta^{*_{11}}+\beta^{*_{1}} \ln F e+\beta^{*_{2}} \ln B r+\beta^{*_{3}} \ln C a+\beta^{*}{ }_{4} \ln D a+\beta^{*_{5}} \ln C O+\beta^{*_{6}} \ln F_{O} \\
& +\beta^{*_{7}} \ln S t+\beta^{*}{ }_{8} \ln E x+\beta^{*_{9}} D_{1}+\beta^{*_{10}} D_{2}+v
\end{aligned}
$$

where $Y$ is average milk yield of the household's milking cows within a calving interval 
measured in kg per milking cow; $\mathrm{Fe}, \mathrm{Br}$ and $\mathrm{Ca}$ are average consumption levels of complete feed, by-products from brewery and cassava-processing industries respectively, in kg per milking cow; $D a$ is average number of man-days used to raise a milking cow, excluding the activity of grass collection; $C o$ is the number of milking cows in the dairy household; $F_{O}$ and $S t$ are average amounts of green fodder and dry straw consumed respectively, in kg per milking cow; Ex expresses experience of the household head measured as her/his number of years practicing dairy farming. The remaining variables are dummy ones: $D_{1}$ is equal to 1 if the household has crossbreeds of $1 / 2 \mathrm{HF}$ blood and/or Red Sindhi in the herd and zero otherwise; $D_{2}$ is equal to 1 if the household cultivates enough green fodder to feed their cows within 10-12 months of a year and zero otherwise. Finally, $\beta_{i}$ and $\beta^{*}{ }_{i}(i=0,1, \ldots, 10)$ are parameters to be estimated; $u$ and $v$ are error terms.

Descriptive statistics for the variables used in the analysis are given in Table 10. The data show that there is a high variation in the number of milking cows, amount of dry straw consumed and man-days employed per milking cow among households. The lowest variation is found for green fodder and complete feed with coefficient of variations (C.V) of 6 to 11 percent.

Table 10. Descriptive statistics of the variables included in the model.

\begin{tabular}{|c|c|c|c|c|c|c|c|}
\hline \multirow{2}{*}{ Names of variables } & \multirow{2}{*}{ Unit } & \multicolumn{3}{|c|}{ Binh Duong (BD) } & \multicolumn{3}{|c|}{ Ho Chi Minh (HCM) } \\
\hline & & Mean & Range & Std. Dev & Mean & Range & Std. Dẹv \\
\hline Milk yield & $\mathrm{kg}$ & $3,644.6$ & $1,071.7$ & 253.8 & $3,897.2$ & $1,000.0$ & 183.1 \\
\hline Complete feed & $\mathrm{kg}$ & $1,194.9$ & 518.1 & 130.6 & $1,265.5$ & 481.1 & 86.3 \\
\hline Brewery's by-product & $\mathrm{kg}$ & $1,519.2$ & $2,618.5$ & 467.6 & $1,621.7$ & $1,679.7$ & 322.9 \\
\hline By-product of CPI & $\mathrm{kg}$ & $1,682.3$ & $3,420.0$ & 946.0 & $2,339.0$ & $2,963.3$ & 627.1 \\
\hline Labor & manday & 106.5 & 149.5 & 34.1 & 100.1 & 154.9 & 44.0 \\
\hline No. of milking cow & head & 3.2 & 8.0 & 1.9 & 3.5 & 9.0 & 2.1 \\
\hline Green fodder & $\mathrm{kg}$ & $10,519.2$ & $2,386.5$ & 624.0 & $9,826.2$ & $3,558.7$ & 811.6 \\
\hline Straw & $\mathrm{kg}$ & 298.0 & $1,141.5$ & 371.0 & 622.8 & $1,213.3$ & 403.8 \\
\hline Experience & year & 4.0 & 12.0 & 2.7 & 5.7 & 10.0 & 2.0 \\
\hline Breed dummy & & 0.5 & 1.0 & 0.5 & 0.4 & 1.0 & 0.5 \\
\hline Fodder dummy & & 0.3 & 1.0 & 0.4 & 0.3 & 1.0 & 0.5 \\
\hline
\end{tabular}

Note: Range is a difference between the maximum value and the minimum value. Std. Dev denote the standard deviation. No. stands for the number. CPI means cassava-processing industry.

Source: Survey, 2003

\section{Test for multicollinearity and heteroscedasticity}

Multicollinearity occurs when any single explanatory variable is highly correlated with a set of other explanatory variables. The simplest and most obvious means of identifying multicollinearity is an examination of the correlation matrix for the independent variables. The presence of high correlation (generally those of 0.90 and above) is the first indication of substantial collinearity (Hair et al., 1995). However, they also suggest that each analyst should determine the degree of collinearity that she/he can accept. According to 
Studenmund (1992), a correlation coefficient greater than 0.80 among the explanatory variables is used as a rule of thumb to indicate the existence of severe multicollinearity. Multicollinearity was tested in a total of four separate models (2 functional forms for 2 provinces). The results indicate that none of the correlation coefficients are more than 0.8 . Except for the correlation of herd size to labor in the log-linear form and the correlation of straw to green fodder in the linear function being rather high (i.e. the figures in $\mathrm{HCM}$ and $\mathrm{BD}$ are 0.76 and 0.79 respectively for the former, or 0.80 and 0.71 respectively for the latter), other explanatory variables in the model have low correlations. This implies that the models are free from severe multicollinearity.

Diagnosis of heteroscedasticity was done using the Breusch-Pagan test. The test involves regressing the squared residuals on explanatory variables thought to be closely associated with the variance of the error term. Then $n R^{2}$ from this regression is asymptotically distributed as $\chi^{2}(k)$ under the null, where $k$ is the number of independent variables and $n$ is the number of observations (Johnston and Dinardo, 1997). In this study, after obtaining the residuals of the estimated regression equations by OLS estimation, the squared residuals were regressed against five variables, namely green fodder, complete feed, dry straw, labor and the number of milking cows. The results show that the values of $n R^{2}$ for the log-linear and linear functional forms in Ho Chi Minh are 5.3 and 0.0 respectively. Similarly, the corresponding figures for Binh Duong are 0.1 and 2.5. The relevant critical value of $\chi^{2}{ }_{0.05}$ (5) is 11.1 , which is higher than the calculated values. Therefore, the hypothesis of homoscedasticity is not rejected in all four models.

\section{Regression results of separated models}

The estimated results of the production functions for the two study sites, named Ho Chi Minh and Binh Duong, are illustrated in Tables 11a and 11b. A remarkable finding inferred from the regression outcomes is that the error variance of the Binh Duong's milk yields is greater than the error variance of the Ho Chi Minh's milk yields. The ratio of RSS

Table 11a. Results of OLS estimation for the linear production function.

\begin{tabular}{|c|c|c|c|c|c|c|}
\hline \multirow{2}{*}{ Variables } & \multicolumn{3}{|c|}{ Ho Chi Minh $(n=40)$} & \multicolumn{3}{|c|}{ Binh Duong $(n=40)$} \\
\hline & Est. value & Std. Error & $T$-ratio & Est. value & Std. Error & T-ratio \\
\hline (Constant) & 1265.071 & 340.219 & $* * * 3.718$ & 1439.290 & 545.842 & $* * 2.637$ \\
\hline Complete feed & 1.618 & 0.163 & $* * * 9.913$ & 0.942 & 0.209 & $* * * 4.513$ \\
\hline Brewery's by-product & 0.009 & 0.058 & 0.147 & 0.200 & 0.065 & $* * 3.068$ \\
\hline By-product of CPI & 0.053 & 0.021 & $* * 2.450$ & 0.103 & 0.034 & ** 3.044 \\
\hline Labor & -0.235 & 0.380 & -0.618 & -1.172 & 0.945 & -1.241 \\
\hline No. of milking cow & 9.073 & 10.397 & 0.873 & -15.061 & 17.913 & -0.841 \\
\hline Green fodder & 0.043 & 0.027 & 1.568 & 0.066 & 0.054 & 1.234 \\
\hline Dry straw & 0.057 & 0.054 & 1.056 & 0.119 & 0.089 & 1.335 \\
\hline Experience & 3.603 & 7.702 & 0.468 & 23.183 & 10.880 & $* * 2.131$ \\
\hline Breed dummy & -119.482 & 35.579 & $* * *-3.358$ & -134.454 & 47.989 & $* *-2.802$ \\
\hline Fodder dummy & 39.489 & 27.340 & 1.444 & 84.327 & 54.020 & 1.561 \\
\hline Adjusted $R$-squares & \multicolumn{3}{|c|}{0.866} & \multicolumn{3}{|c|}{0.754} \\
\hline$F$-statistics & \multicolumn{3}{|c|}{26.1} & \multicolumn{3}{|c|}{12.94} \\
\hline$R S S$ & \multicolumn{3}{|c|}{$130,630.5$} & \multicolumn{3}{|c|}{$460,019.8$} \\
\hline
\end{tabular}


Table 11b. Results of OLS estimation for the Cobb-Douglas production function.

\begin{tabular}{|c|c|c|c|c|c|c|}
\hline \multirow{2}{*}{ Variables } & \multicolumn{3}{|c|}{ Ho Chi Minh } & \multicolumn{3}{|c|}{ Binh Duong } \\
\hline & Est. value & Std. Error & $T$-ratio & Est. value & Std. Error & T-ratio \\
\hline (Constant) & 3.810 & 0.607 & $* * * 6.276$ & 3.692 & 1.299 & $* * 2.843$ \\
\hline Complete feed & 0.553 & 0.053 & $* * * 10.355$ & 0.339 & 0.073 & $* * * 4.641$ \\
\hline Brewery's by-product & 0.021 & 0.025 & 0.820 & 0.004 & 0.003 & 1.423 \\
\hline By-product of CPI & 0.003 & 0.001 & $* * 2.608$ & 0.001 & 0.001 & 0.818 \\
\hline Labor & -0.002 & 0.012 & -0.139 & 0.026 & 0.037 & 0.713 \\
\hline No. of milking cow & 0.014 & 0.010 & 1.405 & 0.016 & 0.021 & 0.760 \\
\hline Green fodder & 0.035 & 0.051 & 0.682 & 0.207 & 0.141 & 1.466 \\
\hline Dry straw & 0.000 & 0.001 & -0.422 & 0.002 & 0.001 & 1.602 \\
\hline Experience & 0.009 & 0.011 & 0.771 & 0.035 & 0.014 & $* * 2.455$ \\
\hline Breed dummy & -0.034 & 0.009 & $* *-3.747$ & -0.052 & 0.015 & $* * *-3.512$ \\
\hline Fodder dummy & 0.009 & 0.007 & 1.209 & 0.029 & 0.016 & $* 1.832$ \\
\hline Adjusted $R$-squares & \multicolumn{3}{|c|}{0.871} & \multicolumn{3}{|c|}{0.699} \\
\hline$F$-statistics & \multicolumn{3}{|c|}{27.42} & \multicolumn{3}{|c|}{10.06} \\
\hline RSS & \multicolumn{3}{|c|}{0.009} & \multicolumn{3}{|c|}{0.042} \\
\hline
\end{tabular}

Note: Three asterisks indicate significance at $1 \%$ level; two and one indicate significance at 5 and 10\% level, respectively. Est., Std. and No. denote estimated, standard and number, respectively. CPI means cassava-processing industry. RSS stands for residual sum of squares.

Source: Survey, 2003 and calculated by SPSS software.

from the data set of Binh Duong to RSS from the data set of Ho Chi Minh in the linear functional form is equal to 3.52. The figure found in the case of the Cobb-Douglas production function is 4.67 , which is higher than the upper critical $F_{(29.99)}$ value of 1.86 at the 5 percent level of significance (or 2.10 at the 2.5 percent level). The difference may be because technological levels of Ho Chi Minh and Binh Duong farmers are not the same. As mentioned in the previous pages, dairy households in Ho Chi Minh are located nearby others, which helps them share everyday knowledge. In other words, their technologies might be quite similar. However, dairy households in Binh Duong are dispersedly throughout in the village, and so they have less chance to share information with each other. Moreover, the range of cow ages in Binh Duong is also larger (see Loan et al., 2004). For example, about 29.2, 11.5 and 3.1 percent of total milking cows in the province have had one, four and over seven times of calving, respectively. The corresponding figures in Ho Chi Minh are 19.2, 17.7 and 0.7 percent. Milk yield varies by the number of calving (Thuong, 2000), so a larger range of milking-cow ages in Binh Duong may partly explain a high variance in the estimated values.

\section{Test for significant differences in the estimated coefficients between the two locations}

One of the classical OLS assumptions is that the error term has a constant variance (no heteroskedasticity). So far, the hypothesis of homoscedasticity has been accepted in the separate models, but the error terms in the data sets of the two locations are significantly different. Therefore, to check whether there are significant differences between the two locations in the coefficients estimated by OLS, we need to make the variance of 
Table 12. A data-matrix for a pooled linear model.

\begin{tabular}{|c|c|c|c|c|c|c|c|c|c|c|c|c|c|}
\hline \multicolumn{2}{|c|}{$\stackrel{\text { Coefficient }}{\longrightarrow}$} & $\beta_{0}$ & $\beta_{1}$ & $\beta_{2}$ & $\ldots$ & $\beta_{9}$ & $\beta_{10}$ & $\delta_{0}$ & $\delta_{1}$ & $\delta_{2}$ & $\cdots$ & $\delta_{10}$ & $\begin{array}{l}\text { Error } \\
\text { term }\end{array}$ \\
\hline \multirow{3}{*}{ 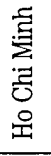 } & $w Y_{1}$ & $w$ & $w \mathrm{Fe}_{1}$ & $w B r_{1}$ & $\ldots .$. & $w D_{11}$ & $w D_{21}$ & 0 & 0 & 0 & $\ldots$ & 0 & $w u$ \\
\hline & $w Y_{2}$ & $w$ & $w \mathrm{Fe}_{2}$ & $w B r_{2}$ & $\ldots$. & $w D_{12}$ & $w D_{22}$ & 0 & 0 & 0 & .... & 0 & $w u$ \\
\hline & $\begin{array}{l}\cdots \\
w Y_{40}\end{array}$ & $\cdots$ & $\begin{array}{c}\ldots . . \\
w F e_{40}\end{array}$ & $\ldots .$. & $\begin{array}{l}\ldots . \\
\ldots . .\end{array}$ & $\begin{array}{c}\ldots . . \\
w D_{140}\end{array}$ & $\begin{array}{c}\ldots . . \\
w D_{2+0}\end{array}$ & $\begin{array}{c}\ldots . \\
0\end{array}$ & $\begin{array}{c}\ldots . . \\
0\end{array}$ & $\begin{array}{c}\ldots . . \\
0\end{array}$ & $\begin{array}{l}\ldots . \\
\ldots\end{array}$ & $\begin{array}{c}\ldots . . \\
0\end{array}$ & $\ldots$. \\
\hline \multirow{3}{*}{$\begin{array}{l}\text { 品 } \\
\text { 号 } \\
\text { 范 }\end{array}$} & $Y_{1}^{*}$ & 1 & $F e_{1}^{\prime}$ & $B r_{1}^{\prime}$ & $\ldots .$. & $D_{11}^{\prime}$ & $D_{21}^{\prime}$ & 1 & $F e_{1}^{\prime}$ & $B r_{1}^{\prime}$ & $\ldots$ & $D^{\prime}{ }_{21}^{\prime}$ & $u^{\prime}$ \\
\hline & $Y^{*}{ }_{2}$ & 1 & $F e_{2}^{\prime}$ & $B r_{2}^{\prime}$ & ...... & $D_{12}^{\prime}$ & $D_{22}^{\prime}$ & 1 & $\mathrm{Fe}_{2}^{\prime}$ & $\mathrm{Br}_{2}^{\prime}$ & $\ldots$ & $D_{22}^{\prime}$ & $u^{\prime}$ \\
\hline & $\begin{array}{l}\ldots . \\
Y^{*}{ }_{40}\end{array}$ & $\begin{array}{c}\cdots \\
1\end{array}$ & $\begin{array}{c}\ldots . \\
F e^{\prime}\end{array}$ & $\begin{array}{l}\ldots \ldots \\
B r_{40}^{\prime}\end{array}$ & $\begin{array}{l}\ldots . . \\
\ldots . .\end{array}$ & $\begin{array}{c}\ldots . . \\
D_{140}^{\prime}\end{array}$ & $\begin{array}{l}\ldots . . \\
D_{240}^{\prime}\end{array}$ & $\stackrel{\ldots}{1}$ & $\ldots .$. & ${ }_{B r_{40}^{\prime}}$ & $\begin{array}{l}\ldots . \\
\ldots .\end{array}$ & $\begin{array}{c}\cdots \cdot \\
D_{240}^{\prime}\end{array}$ & $\cdots$ \\
\hline
\end{tabular}

Note: $\beta_{i}^{\prime}=\beta_{i}+\delta_{i}(i=0,1, \ldots, 10)$

the error terms equal so that a pooled model can be estimated. The procedure would be presented as follows.

Let's consider the linear functional form with the variables defined as before:

$$
\begin{aligned}
& Y=\beta_{0}+\beta_{1} F e+\beta_{2} B r+\beta_{3} C a+\beta_{4} D a+\beta_{5} C o+\beta_{6} F_{O}+\beta_{7} S t+\beta_{8} E x+\beta_{9} D 1+\beta_{10} D_{2}+u \text { (1) }
\end{aligned}
$$

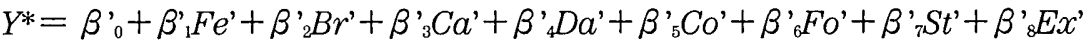

$$
\begin{aligned}
& +\beta_{9}^{\prime} D_{1}^{\prime}+\beta^{\prime}{ }_{10} D_{2}+u^{\prime}(2)
\end{aligned}
$$

where the equation (1) is for Ho Chi Minh, while the equation (2) is for Binh Duong (Note that a pair of variables $\mathrm{Fe}$ and $\mathrm{Fe}$ ' or $\mathrm{Br}$ and $\mathrm{Br}$, etc. have the same meaning). We suppose that $\sigma^{\prime}=w \sigma$, where $\sigma$ and $\sigma^{\prime}$ are standard deviations of the error terms $u$ and $u$; $w$ (weight) is a proportionality coefficient. To make the variance of the error terms in the equation (1) and (2) equal, both sides of the equation (1) are multiplied by $w$. Moreover, let's use $\delta_{i}(i=0,1, \ldots, 10)$ to express differences between the coefficients of $\beta_{i}{ }_{i}$ and $\beta_{i}$ $(i=0,1, . ., 10)$. A pooled model in the linear form is formed as in Table 12.

A similar process is done with the log-linear functional form. A major problem now is how to estimate the value of $w$. We do not know its true value, but may estimate a value range for $w$ based on a confidence interval estimate of the ratio of the two population variances. According to a paper of Sabo (1999), estimates of $100(1-\alpha)$ percent confidence interval involving the variances of two populations are

$$
\frac{s_{2}^{2}}{s_{1}^{2}} F_{1-\frac{\alpha}{2}, \nu, \nu_{z}} \leq \frac{\sigma_{2}^{2}}{\sigma_{1}^{2}} \leq \frac{s_{2}^{2}}{s_{1}^{2}} F_{\frac{\alpha}{2}, \nu, \nu}
$$

where $s^{2}$ and $s_{2}{ }_{2}$ are the estimated variances of random samples drawn from populations 1 and 2 respectively, which are normally distributed; $\sigma^{2}{ }_{1}$ is the variance of population 1 and $\sigma^{2}$ is the variance of population $2 ; \mathrm{F}_{\left(\theta, \nu_{1}, \nu_{2}\right)}$ is the critical value of $\mathrm{F}$ distribution with $\nu_{1}$ and $\nu_{2}$ degrees of freedom and a significance level of $\theta\left(\theta=1-\frac{a}{2}\right.$ for lower critical value, while $\theta=\alpha / 2$ for the upper critical value).

In our case, $\nu_{1}=\nu_{2}=29$, so $\mathrm{F}_{\left(1-\frac{\alpha}{2}\right)}=1 / \mathrm{F}_{\left(\frac{a}{2}\right)}$. We choose $\alpha=0.05$ since this is the most common case, and then $\mathrm{F}_{\left(\frac{a}{2}, 29,29\right)}=2.1010$. If the ratio of the standard deviation from the data set of Binh Duong $\left(\sigma_{2}\right)$ to the standard deviation from the data set of Ho Chi Minh $\left(\sigma_{1}\right)$ is equal to $w$ (i.e. $\sigma_{2}=w \sigma_{1}$ ), we will have the following results after doing some 
calculations:

* For the linear production function

$$
1.2947 \leq w \leq 2.7201
$$

* For the Cobb - Douglas production function

$$
1.4904 \leq w \leq 3.1312
$$

The value ranges of $w$ in two models are not the same, but slightly different. Therefore, we select the same values $w$ of $1.5,2.0,2.5$ and 3.0 for both functional forms. After using these values and estimating the pooled models such as shown in Table 12, we obtain the estimates of coefficients $\beta_{i}$ for the case of Ho Chi Minh and coefficients $\delta_{i}$ indicating differences in the coefficients between Binh Duong and Ho Chi Minh. Tables 13a

Table 13a. OLS estimation results of coefficients $\delta_{i}$ in linear production function.

\begin{tabular}{lrrrrr}
\hline \multirow{2}{*}{ Variables } & Estimated & \multicolumn{4}{c}{$T$-ratios } \\
\cline { 3 - 6 } values $\left(\delta_{i}\right)$ & $w=1.5$ & $w=2.0$ & $w=2.5$ & $w=3.0$ \\
\hline (Constant) & 174.20 & 0.27 & 0.27 & 0.24 & 0.22 \\
Complete feed & -0.68 & $* *-2.49$ & $* *-2.54$ & $* *-2.36$ & $* *-2.17$ \\
Brewery's by-product & 0.19 & $* * 2.11$ & $* * 2.19$ & $* * 2.06$ & $* 1.91$ \\
By-product of CPI & 0.05 & 1.25 & 1.24 & 1.13 & 1.03 \\
Labor & -0.94 & -0.95 & -0.90 & -0.80 & -0.72 \\
No. of milking cow & -24.13 & -1.17 & -1.15 & -1.04 & -0.94 \\
Green fodder & 0.02 & 0.39 & 0.38 & 0.34 & 0.31 \\
Dry straw & 0.06 & 0.59 & 0.58 & 0.53 & 0.48 \\
Experience & 19.58 & 1.45 & 1.46 & 1.34 & 1.23 \\
Breed dummy & -14.97 & -0.25 & -0.25 & -0.23 & -0.21 \\
Fodder dummy & 44.84 & 0.75 & 0.73 & 0.66 & 0.59 \\
\hline
\end{tabular}

Table 13b. OLS estimation results of coefficients $\delta_{i}$ in Cobb-Douglas production function.

\begin{tabular}{lrrrrr}
\hline \multirow{2}{*}{ Variables } & Estimated & \multicolumn{4}{c}{$T$-ratios } \\
\cline { 3 - 6 } values $\left(\delta_{i}\right)$ & $w=1.5$ & $w=2.0$ & $w=2.5$ & $w=3.0$ \\
\hline Constant) & -0.118 & -0.09 & -0.08 & -0.08 & -0.07 \\
Complete feed & -0.215 & $* *-2.35$ & $* *-2.40$ & $* *-2.30$ & $* *-2.16$ \\
Brewery's by-product & -0.016 & -0.52 & -0.62 & -0.68 & -0.73 \\
By-product from CPI & -0.002 & -1.07 & -1.12 & -1.09 & -1.04 \\
Labor & 0.028 & 0.80 & 0.74 & 0.68 & 0.61 \\
No. of milking cow & 0.002 & 0.08 & 0.08 & 0.07 & 0.07 \\
Green fodder & 0.172 & 1.25 & 1.18 & 1.08 & 0.98 \\
Dry straw & 0.002 & 1.63 & 1.62 & 1.53 & 1.41 \\
Experience & 0.026 & 1.40 & 1.45 & 1.40 & 1.32 \\
Breed dummy & -0.018 & -1.08 & -1.07 & -1.01 & -0.94 \\
Fodder dummy & 0.020 & 1.23 & 1.18 & 1.09 & 1.00 \\
\hline
\end{tabular}

Note: Two asterisks indicate significance at $5 \%$ level; one indicates significance at $10 \%$ level. The pooled model has been weighted by $\mathrm{w}$ and has no constant term as a separated model. R-square of this model can not be compared to R-square for models which include a constant term. Therefore, we omit the value of $\mathrm{R}$-squares of the pooled models.

Source: Survey, 2003 and calculated by QBASIC software which is developed by authors 
and $13 \mathrm{~b}$ illustrate a part of those outcomes. The estimated coefficients $\beta_{i}$ are not shown here because they are still the same as the results of Tables $11 \mathrm{a}$ and $11 \mathrm{~b}$ except for some changes in $t$-values. One interesting finding inferred from the estimates of $\beta_{i}$ is that the coefficient $\beta_{6}$ of a green fodder variable in the linear production function becomes significantly different from zero at 10 percent level of significance when the value $w$ is 2.5 or 3.0 .

The outcomes from regression analysis indicate that the estimated values of the coefficients $\delta_{i}$ in the same functional form (i.e. linear form or Cobb-Douglas) with different values of $w$ are exactly same. Only their standard errors and so the $t$-ratios are found to be slightly different. Overall, the $t$-value of coefficient $\delta_{1}$ of the complete feed variable is negative and significant at the 5 percent level of significance for both functional forms. This means that the variable of complete feed in Ho Chi Minh has a higher coefficient than that for Binh Duong. Except for the variable of brewery by-products which is positive and significant at the 5 or 10 percent level of significance in the linear production function, other remainders are not significant. In other words, there is not a significant difference between the two locations in slopes of some variables such as the by-products from the cassava-processing industry, labor, the number of milking cows, green fodder, dry straw, education, and dummy variables for fodder and breed.

The higher positive impact of complete feed on milk yield in Ho Chi Minh may be partially explained by the better quality of its cow breeds. Having practiced dairy farming longer, dairy farmers in Ho Chi Minh have more chance to select good cows from their own cow herds. The survey reveals that their milking cows with poor performance are sold to other places including Binh Duong. Feed (nutrition) is not used solely for milk production, but also for the maintenance of the body, and growth and development of the fetus. Therefore, the same amount of feed fed to different cows may result in various yields. In addition, a higher percentage of milking cows with four and fifth calvings ${ }^{(6)}$ in Ho Chi Minh might also explain the situation (i.e. this percentage in Binh Duong is 14.5 percent, compared to 26.9 percent in Ho Chi Minh). Another reason may relate to the feeding method. Dairy farmers in the study areas usually use by-products from food-processing industries (e.g. by-products from brewery and cassava-processing industries) to substitute partially for complete feed. However, their proportions in the ration of the cows' concentrated feed are different by household. Ho Chi Minh farmers seem to use a higher ratio of by-products in the ration than Binh Duong farmers. This fact might lead to a higher impact of additional use of complete feed on milk yield in Ho Chi Minh when compared to that of Binh Duong. It also may explain why additional use of brewery by-products in Ho Chi Minh has a lower effect on milk yield in the case of the linear production function.

\section{An analysis of the estimated results}

In Ho Chi Minh, the variables named complete feed, by-product from the cassava processing industry and breed dummy have significant effects on milk yield at the 1 or 5 percent level in both functional forms. Positive coefficients for complete feed and

\footnotetext{
(6) According to Thuong (2000), a milking cow usually attains higher yield at the fourth and fifth lactations.
} 
by-product from the cassava-processing industry imply that an increase in use of these inputs may increase milk yield. From the linear production function, for example, feeding $1 \mathrm{~kg}$ of complete feed more in Ho Chi Minh may raise milk yield by $1.6 \mathrm{~kg}$ under the current levels of inputs, keeping other variables constant. Based on the survey result, the lowest milk price the farmer received was 2.7 thousand $\mathrm{VND} / \mathrm{kg}$, and the highest price of complete feed she/he paid to the trader was 2.6 thousand VND $/ \mathrm{kg}$. Thus, it is worth feeding more complete feed to get a higher net return under the current input levels. Although it has a positive effect, the marginal revenue gained by using an additional kilogram of by-product from the cassava-processing industry is smaller than its marginal cost (the average price of this input in the province was 0.25 thousand VND $/ \mathrm{kg}$ ). It means that the dairy farmer may not get a higher net return by feeding more of the by-product if its price and the milk price are unchanged. The negative and significant sign of the breed dummy variable indicates an additional average yield obtained by households without crossbreeds of Red Sindhi and/or F1 in their cow herds as compared to households having them, holding the inputs constant.

Regarding the linear production function in Binh Duong, the variables of complete feed and by-products from brewery and cassava-processing industries have positive and significant effects on milk yield at the 1 or 5 percent level of significance. Comparison of the ratio between marginal value of input (evaluated at mean levels) and its price shows that the above inputs are under-utilized. Therefore, it is possible for dairy farmer to increase their net return by using more of those inputs. In Binh Duong, unlike Ho Chi Minh, the coefficient of the experience variable is positive and significant at the 5 percent level. This implies that, in Binh Duong, the dairy farmer with more experience might have a significantly higher milk yield than the farmer with less experience. This was not the case in Ho Chi Minh and may be partially because there is a considerable difference in experience among the dairy farmers in Binh Duong, who have less chance to share everyday knowledge than the farmers in Ho Chi Minh. From the survey data, the percentages of farmers with 1-3 and 3-9 years of experience in dairy farming in Ho Chi Minh were 12.5 and 82.5 percent respectively. Meanwhile, the corresponding figures in Binh Duong were 52.5 and 42.5 percent.

The empirical evidence from regression analysis also shows that different forms of production function may result in different estimated outcomes. Comparison of the estimated results between the two functional forms in Binh Duong gives an example. The level of significance of the estimated coefficients, such as by-products from the brewery and cassava-processing industries, and the fodder dummy, between the linear function and the log-linear function are not the same. In addition, their effects on milk yield may be also different. For instance, the estimated marginal product of the experience variable in the linear production function is $23.2 \mathrm{~kg}$, while in the log-linear production function it is 31.9 (evaluated at mean levels). This implies that the selection of functional form has considerable impact on the estimated outcomes. By examining quasi-R squares of the separate models ${ }^{(i)}$, significance levels of the estimated coefficients and the degree to which the estimated coefficients conform to our expectation, and the linear functional form seems to have a better overall quality than the log-linear one.

It is worth noting here that the estimated coefficient of the milking-cow numbers variable is not significantly different from zero, supporting the idea that there is no econo- 
my of scale for the range of milking-cow numbers considered. However, this result may not imply that herd size has no effects at all on the household's return. In fact, there were negatively significant correlations between milking-cow number and man-day per milking cow for some production activities (e.g. cleaning the shed and the cow, feeding). The correlation coefficient between the herd size and man-days of hygienic activities per milking cow was minus 0.66 , which was significant at the 1 percent level. The correlation was stronger between the herd size and man-days of feeding per milking cow, with a correlation coefficient of minus 0.75 . Therefore, the herd size was unlikely to have significant effects on milk yield, but might have significant effects on labor use for some activities and on capital use as well. The analysis implies that when opportunities for off-farm jobs increase, it may be more advantageous to have a large number of cows.

\section{CONCLUSIONS AND SUGGESTIONS}

Results from the survey indicate that there are close and strong relationships among dairy farmers in the study areas. They shared the experience of raising dairy cows and provided low interest loans to each other. In addition, cooperation between dairy households and related organizations (i.e. milk-processing factories, local authorities, veterinary department, banks and extension centers) in some fields such as milk collection, herd management and loans has existed and gradually been improving in the region. All this provides a basis for further development of dairy production.

Although achieving certain progress, the supportive organizations in the region have still played a limited role in providing dairy farmers with cow breeds, technical information and high quality AI and veterinary services. Evidence from analysis of the survey data shows a high percentage of dairy households getting access to cow breeds and technical information from their co-producers rather than supportive organizations. In addition, almost 18 percent of the dairy cows fell pregnant after more than two times of AI. Thus, the improvement of extension, veterinary and breeding networks at the raising zones may be very necessary.

The unstable and relatively low ratio of milk price to feed price was considered as another constraint for the expansion of dairy farming. In spite of fluctuations both up and down, the price of complete feed in general tended to increase from 1995 to 2003. Meanwhile, the milk price offered by Vinamilk, a main buyer in the region, has been fixed since 1995. Moreover, the ratio was found to be lower than that of other countries (i.e. Thailand or Japan). Therefore, institutional interventions of the government may be necessary to keep the ratio more reasonable (e.g., a decrease in the import duty level of raw materials used in feed-processing factories may result in lower production cost per $\mathrm{kg}$ of

(i) When the dependent variable is transformed from its linear version, the $R$ square value cannot be used for comparing the fit of the nonlinear equation with the original one. The way to get around this problem is to calculate a quasi- $R$ square by transforming the predicted values of the nonlinear dependent variable into a form that is directly comparable to the original dependent variable (see Studenmund and Cassidy, 1987 for more detail). In this study, the quasi- $R$ square for the log-linear equation in Ho Chi Minh is 0.899 , which is equivalent to the $R$ square of 0.90 in the linear equation. At the same time, the quasi- $R$ square for the log-linear equation in Binh Duong is 0.772 , which is lower than the $R$ square of 0.817 in the linear equation. 
feed and then cheaper price of feed).

It seems that dairy farmers have not yet recognized the important role of record keeping activities. About half of the surveyed households did not report any information related to their cows in the past 5 months. Therefore, cows being bought or sold at market without individual records were quite common in the study areas. This fact shows an urgent need to improve herd management in the region. Authorities should not only train dairy farmers to keep records but also supervise their recording processes.

Dairying in the region still has the characteristic of small scale production. Dairy farmers tend to utilize family labor to collect green fodder. Only a small proportion of them cultivated enough grass for their cows. Natural fodder is assessed to have both a lower quality and an unstable source of supply, while a well-managed market for high quality fodder has not been formed in the study areas. Therefore, development of the linkage between grass production and dairying may be necessary for sustainable development of the dairy sector.

Most cow manure was treated by traditional methods, which still resulted in environmental pollution. Meanwhile, the number of households using biogas generators was small. As a result, both dairy farmers and non-dairy farmers have been affected by nuisances caused by dairying such as malodors and flies. These findings warn us of serious environmental pollution in the near future if we do not take it into account immediately. The government should give partial financial support to dairy farmers to help them install biogas generators, so that pollution is effectively prevented.

The results from regression analyses of production functions show that dairy farmers in the study areas might increase milk yields by additional use of some inputs such as complete feed, and by-products from brewery and cassava-processing industries. In addition, kinds of cow breed and the experience of the household head also have significant effects on milk yield. The estimated variances of error terms and coefficients of the complete feed variable are found to be significantly different between Ho Chi Minh and Binh Duong. Assessment of input use at mean levels indicates that complete feed is under utilized at the given prices of milk and complete feed. The findings suggest dairy farmers may increase the amount of complete feed to attain higher net returns, although the problem of risk associated with this strategy is a question for future study.

\section{REFERENCES}

AFEC (Agricultural and Forestry Extension Center) 2002 Situation of Dairy Cow Raising in 2002. Report was presented at a meeting on dairy production in Ho Chi Minh on $10^{\prime \prime}$ December, Ministry of Agriculture and Rural Development (in Vietnamese)

Anh, T. K. 2003 Some Incentive Policies for Development of Animal Sub-sector and Development Orientations in Future. A report in http://www.ven.vnn.vn/hoatdong/ hd_2003/hd_20_6_2003_3.htm

Christopher L. D., C. A. Narrod and M. T. Marites 2003 Project on Livestock Industrialization, Trade and Social-Health-Environment Impacts in Developing Countries. The report is submitted to the Food and Agricultural Organization of the United Nations in http://www.virtualcentre. org/en/res/awi/reports/x6170e/x6170e00.htm

HDARD (Ho Chi Minh Department of Agriculture and Rural Development) 2003 Report on Management and Development of Cow Herd in Ho Chi Minh city. The report was submit to Ministry of Agriculture and Rural Development, Agricultural and Forestry Extension Center, Ho Chi Minh (in Vietnamese)

Hair, J. F., R. E. Anderson, R. L. Tatham and W. C. Black 1995 Multivariate Data Analysis with 
Readings. $4^{\text {th }}$ edition, Prentica-Hall International, Inc, United State of America

Hien, N. T. M. 2003 An Economics Study of Rice Production in the Mekong Delta, Vietnam. (Doctor Thesis), Graduate School of Bioresource and Bioenvironmental Sciences, Kyushu University

Hoa, T. A and T. D. Luan 2003 Economic Analysis of Various Livestock Waste Treatment and Policy Options. A paper was presented at the workshop in Bangkok (Thailand) held on $10^{\prime \prime}-12^{\prime \prime}$ September by $A W I$ (from http://www.virtualcentre.org/en/ res/awi/gefpro/downloads/vietecon.ppt)

Japan Dairy Council Japan 2002 Dairy Farming for Yesterday, Today and Tomorrow in http://jdc. lin.go.jp/eng/eng02.htm

Johnston, J. and J. Dinardo 1997 Econometric Methods. McGRAW-Hill Companies, Inc.

Lich, L. B. 2003 Orientation of Feed Production in Vietnam. Journal of Technical and Scientific Information of Animal Husbandry, 1: 11-15

Loan, C. K. T., H. Yokogawa and T. Kawaguchi 2004 The Economics of Dairy Cow Raising in the South East of Vietnam. Journal of the Faculty of Agiculture, Kyushu University, 49(2): 497-512

Phuong, T. T. 1996 Environmental Management and Policy-Making in Vietnam. A paper was presented at Seminar on Environment and Development in Vietnam, held on 6-7" December at Australian National University (from http://coombs.anu.edu.au/ vern/env_dev/seminar96.html)

Sabo, D. W. 1999 Testing Hypothesis Involving the Variances of Two Populations in http://www. math.bcit.ca/faculty/david_sabo/apples/math2441/section9/comp2popvarht/diff2popvarsht.doc

Statistical Office in Ho Chi Minh 2003 Statistical Yearbook 2002. Statistical Office of Ho Chi Minh

Studendmund, A. H. 1992 Using Econometrics: A Practical Guide. $2^{\text {ml }}$ edition, HarperCollins Publisher, New York

Studenmund, H. and E. J. Cassidy 1987 Using Econometrics-Practical Guide. Little, Brown and Company Limited, Canada

Thuong, N. V. 2000 Technique of Cow Raising at Farm Household Level. Agricultural Publisher, Hanoi (in Vietnamese)

Van, H. 2002 Development of Cow Herd in the Southern Vietnam. Newspaper of Sai Gon Economy, January $25^{\text {th }}$ (in Vietnamese) 